\title{
ATR-FTIR and XPS Evaluation of Alkyl Immobilization by Hydrosilylation on n-Si(111) for Photoelectrochemical Cell Electrode
}

\section{Toshihito Ohtake}

Department of Mechanical Systems Engineering, Faculty of Engineering, Aich University of Technology, Gamagori, Japan. Email: ohtake@aut.ac.jp

Received July $16^{\text {th }}, 2013$; revised August $20^{\text {th }}, 2013$; accepted August $30^{\text {th }}, 2013$

Copyright (C) 2013 Toshihito Ohtake. This is an open access article distributed under the Creative Commons Attribution License, which permits unrestricted use, distribution, and reproduction in any medium, provided the original work is properly cited.

\begin{abstract}
An electrode development was needed with high efficiency and low costs as next generation solar cells. We attempted the electrode fabrication for a photoelectrochemical cell by immobilizing functional groups on a n-Si(111) surface. The immobilization was applied by hydrosilylation terminated with ester (hydrophobic) or carbonyl (hydrophilic) group. Results confirmed the immobilization on the Si surface by measuring ATR-FTIR and XPS.
\end{abstract}

Keywords: ATR-FTIR; XPS; Si Surface; Hydrosilylation; Immobilization; Photoelectrochemical Cell

\section{Introduction}

We are faced with problems about energy and global environment, and solar energy has been noticed to solve them. Solar power generation is studied actively, and high efficient solar cells are produced recently. However, there are high costs to be complicated manufacturing processes or the use of expensive materials for transparent conductive oxide including indium etc. Hence, solar cell developments of high efficiently and low costs are required to spread them largely $[1,2]$.

It is known that photoelectrochemical cell (PEC) by using n-Si electrode onto supporting with Pt shows high open circuit photovoltage over $0.6 \mathrm{~V}$ comparing with conventional p-n junction Si solar cell [3]. PEC is interested with very low costs, but the stability of Si electrode in electrolytic solution is not so good to form $\mathrm{SiO}_{2}$ layer on the surface by oxidation of $\mathrm{Si}$.

Researches have been reported about alkyl termination on $\mathrm{Si}$ surface [4-9]. Especially bio-tips for detecting DNA or protein etc. are applied by immobilizing functional groups [10]. On the other hand, it is known that the immobilization particularly makes Si surface stable for oxidation [5,11,12]. Furthermore, controls of electrode properties are expected for the termination by the functional groups on Si surface.

In this study, termination with ester or carboxy group was carried out by a hydrosilylation on hydrogen-terminated Si surface. The termination was estimated by ATRFTIR and XPS measurement, simultaneously with evaluation of Si surface oxidation.

\section{Methodology}

A n-Si(111) was performed by RCA washing to terminate with hydrogen after washed with aceton to remove organic matters. The Si was etched to termination of hydrogen by $5 \% \mathrm{HF}$ solution for $5 \mathrm{~min}$ and $40 \% \mathrm{NH}_{4} \mathrm{~F}$ for $15 \mathrm{~min}$. The ester termination directly was made use of the hydrosilylation on the hydrogen-terminated $\mathrm{Si}$ in Scheme 1. The $\mathrm{Si}$ was immersed in $0.1 \mathrm{M}$ methyl propiolate/hexan solution for $24 \mathrm{~h}$ at room temperature under Ar atmosphere in schlenk flask, after washed with diethyl ether. Furthermore, the immersed time was

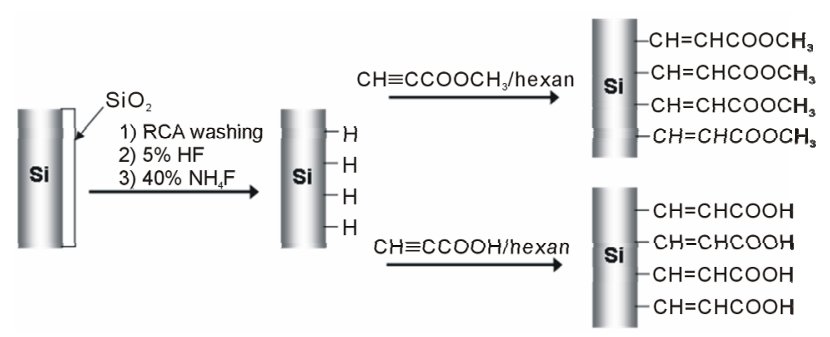

Scheme 1. Termination process by hydrosilylation. 
changed from $2 \mathrm{~h}$ to $15 \mathrm{~h}$ in methyl propiolate/hexan solution. Carbonyl group termination on the hydrogen-terminated $\mathrm{Si}$ was performed by the hydrosilylation with an unsaturated carboxylic acid. Similarly, the Si was immersed in $0.1 \mathrm{M}$ propiolic acid/hexan solution for $24 \mathrm{~h}$. The Si surface was measured by MIR-FTIR and XPS, and cumulative number was 256 and 64 respectively.

\section{Results and Discussion}

\subsection{MIR-FTIR Measurement}

The ester termination on Si surface was estimated about $\mathrm{C}=\mathrm{C}, \mathrm{C}=\mathrm{O}$ and $\mathrm{Si}-\mathrm{H}$ stretching vibration. Figure 1 shows MIR-FTIR spectra of the $\mathrm{n}-\mathrm{Si}(111)$ surface terminated with methyl propiolate by $24 \mathrm{~h}$ immersing time in line (a) and terminated with hydrogen by RCA washing in line (b). This result would show the ester termination by applying methyl propiolate because peaks of $\mathrm{C}=\mathrm{O}$ at 1728 and $\mathrm{C}=\mathrm{C}$ at 1588 stretching vibration based on the ester was appeared, and $\mathrm{Si}-\mathrm{H}$ stretching vibration at 2083 $\mathrm{cm}^{-1}$ was disappeared simultaneously.

Furthermore, Figure 2 shows the spectra of the termination by a various methyl propiolate immersing time from 1 to $24 \mathrm{~h}$. We obtained that the intensity of $\mathrm{C}=\mathrm{O}$ and $\mathrm{C}=\mathrm{C}$ peaks was increasing and that of $\mathrm{Si}-\mathrm{H}$ peak was decreasing with immersing time. These results would conclude that the ester termination by the hydrosilylation progressed instead of the hydrogen termination on $\mathrm{Si}$ surface.

The carbonyl group termination on $\mathrm{Si}$ surface was similarly evaluated in Figure 3 line (a). The spectra showed peaks of $\mathrm{C}=\mathrm{O}$ at $1709 \mathrm{~cm}^{-1}$ and $\mathrm{C}=\mathrm{C}$ at 1586 stretching vibration based on the carbonyl group, hence the Si surface would be immobilized by the carbonyl group. Moreover, spectra of the sample applied in 0.01 $\mathrm{M} \mathrm{NaOH}$ solution obtained a peak of $\mathrm{C}=\mathrm{O}$ based on -COO- at about $1550 \mathrm{~cm}^{-1}$ instead of decrease in the

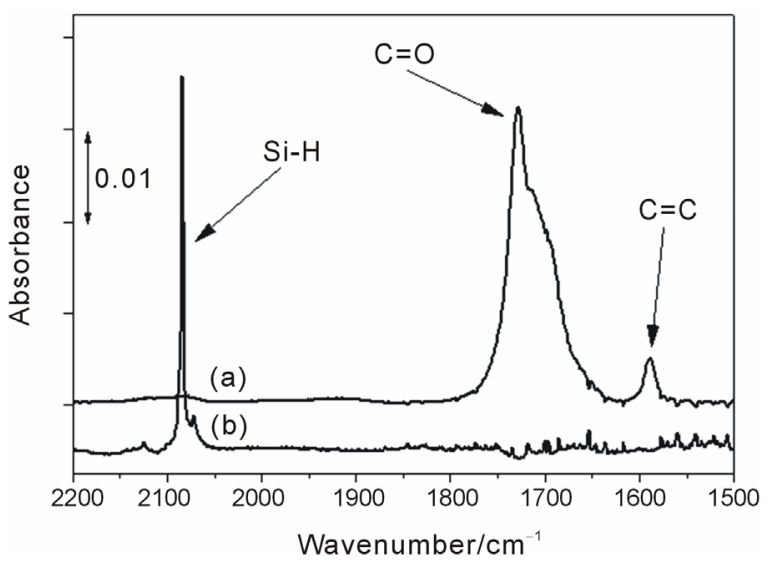

Figure 1. MIR-FTIR spectra of (a); methyl propiolate termination, (b): hydrogen termination on $\mathrm{n}-\mathrm{Si}(111)$ surface.

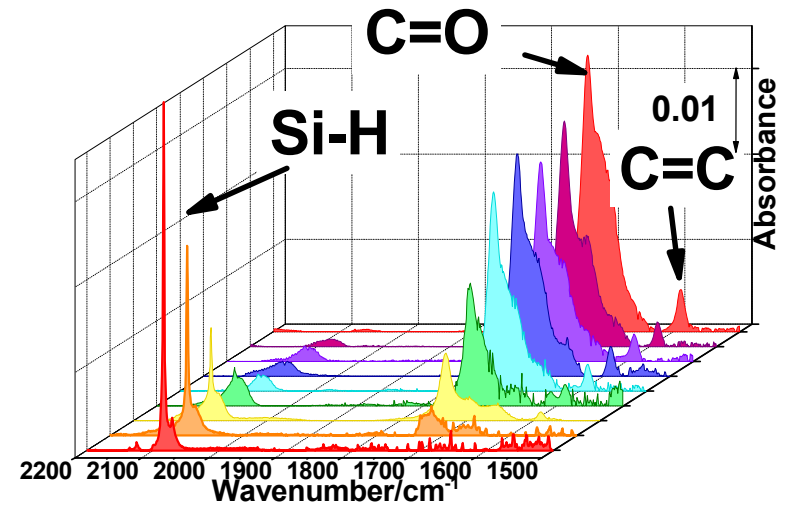

Figure 2. Dependence of immersing time in methyl propiolate on MIR-FTIR spectra. The time is $1,3,6,9,12,15,18$, 21, $24 \mathrm{~h}$ from the front row.

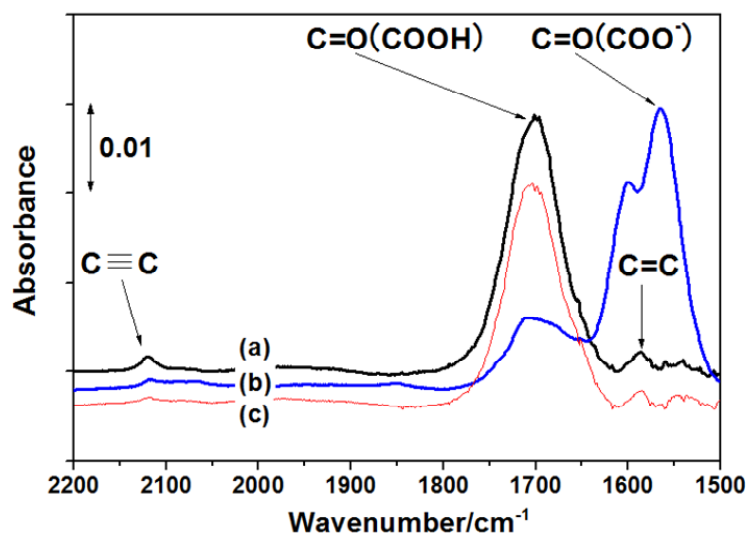

Figure 3. MIR-FTIR spectra on Si surface (a): carboxy group termination, (b): after immersing in $0.01 \mathrm{M} \mathrm{NaOH}$ and (c): after immersing in 2.0 M HCl subsequently.

peak of $\mathrm{C}=\mathrm{O}$ based on $-\mathrm{COOH}$ at $1709 \mathrm{~cm}^{-1}$ showed in Figure 3 line (b). Subsequently, spectra of the sample applied in $2.0 \mathrm{M} \mathrm{HCl}$ aq showed the peak of $\mathrm{C}=\mathrm{O}$ based on $-\mathrm{COOH}$ at $1709 \mathrm{~cm}^{-1}$ instead of disappear at the peak based on -COO- at about $1550 \mathrm{~cm}^{-1}$ in Figure 3 line (c). Hence, the carbonyl group terminated on the Si surface will cause acid-base reaction with the $\mathrm{NaOH}$ or $\mathrm{HCl}$ solution. Then, a peak of $\mathrm{C} \equiv \mathrm{C}$ stretching vibration at 2119 $\mathrm{cm}^{-1}$ disappeared by the acid-base reaction. However the peak is not clear yet, dimers formed between the immobilized carbonyl group and an unreacted propiolic acid might exist on the Si surface in Scheme 2. Consequently, the peak based on $\mathrm{C} \equiv \mathrm{C}$ at $2119 \mathrm{~cm}^{-1}$ might be appeared by the termination, and disappeared by acid-base reactions.

\subsection{XPS Measurement}

Figure 4 shows XPS spectra of C1s about the ester termination (a) and the carbonyl group termination (b) on the Si surface, which indicated three peaks of $\mathrm{C}-\mathrm{H}, \mathrm{C}-\mathrm{O}$ 


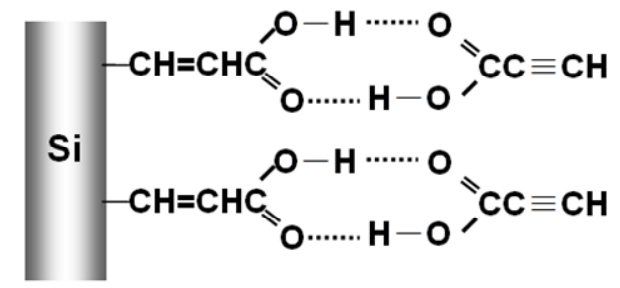

Scheme 2. Possibility of dimers formed between the immobilized carboxy group and an unreacted propiolic acid.

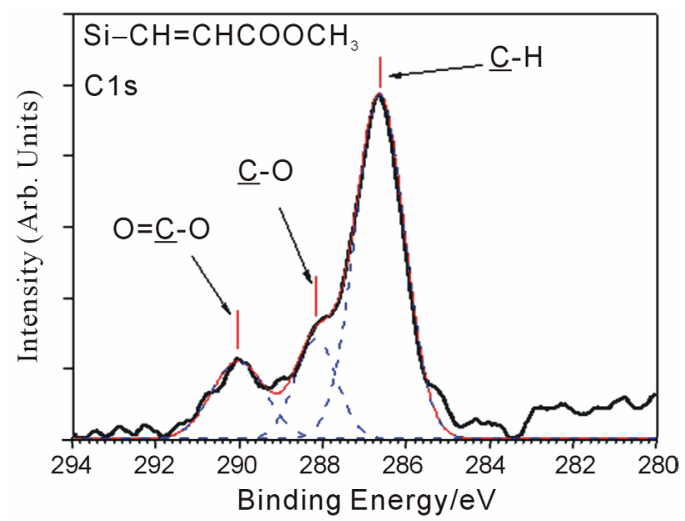

(a)

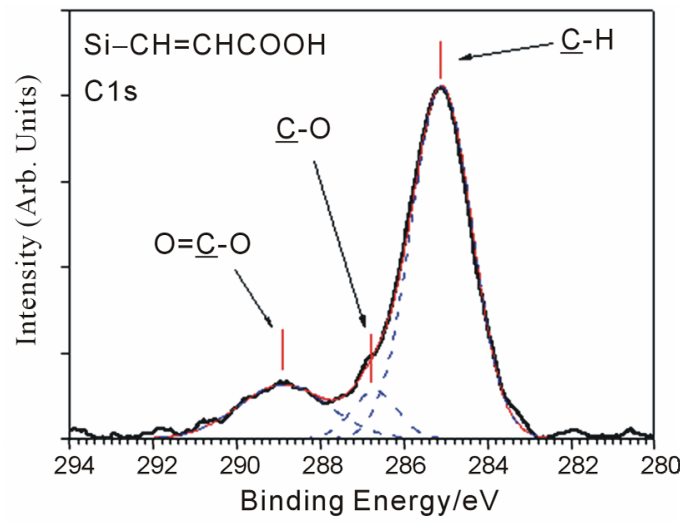

(b)

Figure 4. XPS spectra of C1s (a); the ester, (b): the carbonyl group termination on $\mathrm{n}-\mathrm{Si}(111)$ surface.

and $\mathrm{O}=\mathrm{C}-\mathrm{O}$ [13]. These results would confirm the termination by the ester or carbonyl group followed by the MIR-FTIR measurements in the same way. The oxidation on the Si surface was estimated by the spectra of $\mathrm{Si} 2 \mathrm{p}$ in Figure 5. A spectrum for (a); the hydrogen terminated on the Si surface showed no oxidation at about $103 \mathrm{eV}$ except a main peak at about $100 \mathrm{eV}$ [14]. Although a spectrum for (b); the ester terminated on the $\mathrm{Si}$ surface indicated a peak barely at about $103 \mathrm{eV}$, the surface would not be effected by the oxidation. A spectrum for (c); the carbonyl group terminated on the Si surface was obtained slightly at about $103 \mathrm{eV}$, which will be caused by immersing in the propiolic acid/hexan solu-

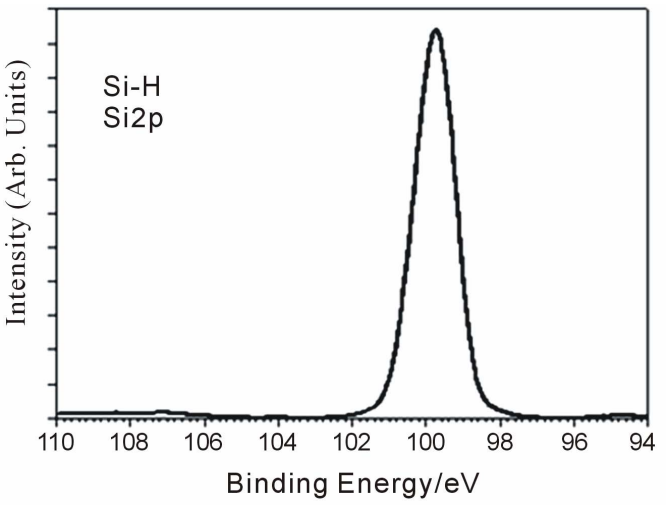

(a)

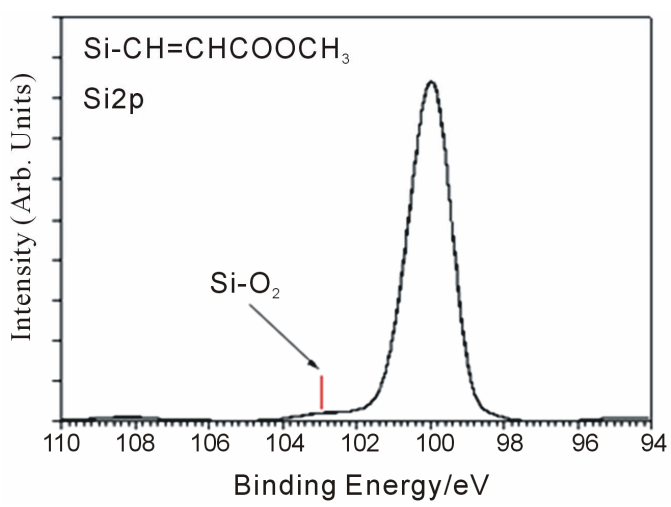

(b)

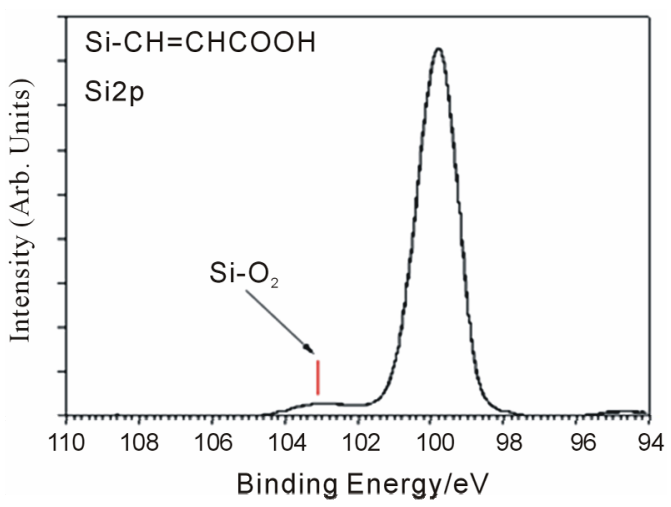

(c)

Figure 5. XPS spectra of Si2p (a); the hydrogen, (b); the ester, (c); the carbonyl group termination on $\mathbf{n}-\mathrm{Si}(111)$ surface.

tion. The peak for the carbonyl group termination was larger than that of the ester termination. This result might show a difference of hydrophobic or hydrophilic functional groups. These terminated $\mathrm{Si}$ would be applied as the functional electrodes.

\section{Conclusion}

The hydrosilylation on the hydrogen-terminated Si reacted as the ester termination in the propiolate/hexan 
solution, and was confirmed by the MIR-FTIR measurements. Similarly, the carbonyl group termination was also performed and estimated in the propiolic acid/hexan solution, and the Si surface was immobilized by the hydrophobic or hydrophilic functional groups. Although the Si surface was hardly oxidized by XPS measurement, it will be necessary to form more pure Si surface.

\section{REFERENCES}

[1] K. L. Chopra, P. D. Paulson and V. Dutta, "Thin-Film Solar Cells: An Overview," Progress in Photovoltaics, Vol. 12, No. 2-3, 2004, pp. 69-92. doi:10.1002/pip.541

[2] A. Goetzberger, C. Hebling and H. W. Schock, "Photovoltaic Materials, History, Status and Outlook," Materials Science and Engineering: Reports, Vol. 40, No. 1, 2003, pp. 1-46. doi:10.1016/S0927-796X(02)00092-X

[3] Y. Nakato, K. Ueda, H. Yano and H. Tsubomura, "Effect of Microscopic Discontinuity of Metal Overlayers on the Photovoltages in Metal-Coated Semiconductor-Liquid Junction Photoelectrochemical Cells for Efficient Solar Energy Conversion," The Journal of Physical Chemistry, Vol. 92, No. 8, 1988, pp. 2316-2324. doi:10.1021/j100319a043

[4] M. R. Linford and C. E. D. Chidsey, "Alkyl Monolayers Covalently Bonded to Silicon Surfaces," Journal of the American Chemical Society, Vol. 115, No. 26, 1993, pp. 12631-12632. doi:10.1021/ja00079a071

[5] M. R. Inford, P. Fenter, P. M. Eisenberger and C. E. D. Chidsey, "Alkyl Monolayers on Silicon Prepared from 1-Alkenes and Hydrogen-Terminated Silicon," Journal of the American Chemical Society, Vol. 117, No. 11, 1995, pp. 3145-3155. doi:10.1021/ja00116a019

[6] A. Bansal, X. L. Li, I. Lauermann, N. S. Lewis, S. I. Yi and W. H. Weinberg, "Alkylation of Si Surfaces Using a Two-Step Halogenation/Grignard Route," Journal of the American Chemical Society, Vol. 118, No. 30, 1996, pp. 7225-7226. doi:10.1021/ja960348n
[7] J. M. Buriak, "Organometallic Chemistry on Silicon Surfaces: Formation of Functional Monolayers Bound through Si-C Bonds," Chemical Communications, Vol. 1999, No. 12, 1999, pp. 1051-1060. doi:10.1039/a900108e

[8] J. M. Buriak, "Organometallic Chemistry on Silicon and Germanium Surfaces," Chemical Reviews, Vol. 102, No. 5, 2002, pp. 1271-1308. doi:10.1021/cr000064s

[9] D. D. M. Wayner and R. A. Wolkow, "Organic Modification of Hydrogen Terminated Silicon Surfaces," Journal of the Chemical Society, Perkin Transactions, Vol. 2, No. 1, 2002, pp. 23-24.

[10] T. Strother, W. Cai, X. S. Zhao, R. J. Hamers and L. M. Smith, "Synthesis and Characterization of DNA-Modified Silicon(111) Surfaces," Journal of the American Chemical Society, Vol. 122, No. 6, 2000, pp. 1205-1209. doi:10.1021/ja9936161

[11] A. Bansal and N. S. Lewis, "Stabilization of Si Photoanodes in Aqueous Electrolytes through Surface Alkylation," The Journal of Physical Chemistry B, Vol. 102, No. 21, 1998, pp. 4058-4060. doi:10.1021/jp980679h

[12] W. J. Royea, A. Juang and N. S. Lewis, "Preparation of Air-Stable, Low Recombination Velocity Si(111) Surfaces through Alkyl Termination," Applied Physics Letters, Vol. 77, No. 13, 2000, pp. 1988-1990. doi: $10.1063 / 1.1312203$

[13] T. Vallant, H. Brunner, J. Kattner, U. Mayer, H. Hoffmann, T. Leitner, G. Friedbacher, G. Schügerl, R. Svagera and M. Ebel, "Monolayer-Controlled Deposition of Silicon Oxide Films on Gold, Silicon, and Mica Substrates by Room-Temperature Adsorption and Oxidation of Alkylsiloxane Monolayers," The Journal of Physical Chemistry B, Vol. 104, No. 22, 2000, pp. 5309-5317. doi:10.1021/jp000006a

[14] J. B. Danner and J. M. Vohs, "Surface Reactions during the Growth of $\mathrm{SiO}_{2}$ Thin Films on $\mathrm{Si}(100)$ Using Tetraethoxysilane," Langmuir, Vol. 10, No. 9, 1994, pp. 3116 3121. doi: $10.1021 / \mathrm{la} 00021 \mathrm{a} 040$ 